Please cite as: "de Lenne, O., \& Vandenbosch, L. (2017). Fashion Media and Sustainable Fashion Buying Behavior. Journal of Fashion Marketing and Management: An International Journal, 21 (4). doi : 10.1108/JFMM-11-2016-0101”

Fashion Media and Sustainable Fashion Buying Behavior.

Orpha de Lenne, $\mathrm{Ma}^{1}$ \& Laura Vandenbosch, $\mathrm{PhD}^{1,2}$

Affiliations: ${ }^{1}$ School for Mass Communication Research, Faculty of Social Sciences, University of Leuven, Leuven, Belgium affiliated with Research Foundation Flanders (FWOVlaanderen), ${ }^{2}$ MIOS (Media, ICT, and Interpersonal Relations In Organisations and Society), University of Antwerp;

Email addresses: orpha.delenne@kuleuven.be; laura.vandenbosch@kuleuven.be

Address correspondence to: Laura Vandenbosch, School for Mass Communication Research, Faculty of Social Sciences, University of Leuven, Parkstraat 45 (PO box 3603), B-3000 Leuven, Belgium. E-mail: laura.vandenbosch@soc.kuleuven.be Tel: + 3216323202

Acknowledgements. No conflicts of interest to declare. 


\begin{abstract}
Purpose - Using the theory of planned behavior, this paper examined the relationships between different types of media and the intention to buy sustainable apparel and tested whether attitudes, social norms, and self-efficacy beliefs may explain these relationships.
\end{abstract}

Design/methodology/approach - A cross-sectional survey study was conducted among 681 young adults (18-26 years old).

Findings - Exposure to social media content of sustainable organizations, eco-activists and sustainable apparel brands and social media content of fashion bloggers and fast fashion brands predicted respondents' attitudes, descriptive and subjective norms, and self-efficacy beliefs regarding buying sustainable apparel. In turn, attitudes, descriptive norms, and self-efficacy beliefs predicted the intention to buy sustainable apparel. Fashion magazines predicted the intention through self-efficacy. Specialized magazines did not predict the intention to buy sustainable apparel.

Research limitations/implications - Results should be generalized with caution as the current study relied on a convenience sample of young adults. The cross-sectional study design limits the ability to draw conclusions regarding causality. Actual behavior was not addressed and needs to be included in further research.

Practical implications - The present study hints at the importance of social media to affect young consumers' intentions to buy sustainable apparel. Sustainable apparel brands should consider attracting more young social media users to their social media pages.

Originality/value - This study is one of the first to examine the potential of different media to promote sustainable apparel buying intention.

Keywords Social media, Magazines, Theory of planned behavior, Sustainable apparel, Fast fashion 
MEDIA AND CONSUMPTION OF SUSTAINABLE APPAREL

\section{Media and Sustainable Apparel Buying Intention}

\section{Introduction}

Some sectors of the fashion industry have adopted unethical production processes with negative social (Hobson, 2013; Taplin, 2014) and environmental consequences (Shen, 2014). For example, a quarter of all pesticides in the US are used for cotton production (Luz, 2007). Activists and scholars have called attention for more ethical awareness in the fashion industry (Clark, 2008; Niinimäki and Hassi, 2011; Ozdamar Ertekin and Atik, 2015). Hence, more sustainable clothing options, such as sustainable apparel, have emerged.

Consumers have been hesitant to adopt sustainable apparel because of style and price reasons (Joergens, 2006). Sustainable apparel brands have tried to address this problem by transparent communication about sustainability (Fuentes, 2015). However, consumers still lack knowledge about sustainable apparel brands (Hill and Lee, 2012). As such, research is needed on how the communication about sustainable apparel can be improved.

Little is known about the influence of exposure to different media genres on the popularity of sustainable apparel. Literature on social media influencers (Balakrishnan et al., 2014; Lee and Watkins, 2016; Pihl and Sandström, 2013) and fashion magazines (Steele and Brown, 1995) suggests they play a role in consumers' buying behavior, but empirical evidence showing the importance of media in the consumption of sustainable apparel is lacking. More precisely, we do not know whether social media and magazines have the potential to increase consumers' interest in sustainable apparel.

The current cross-sectional study among young adults aimed to address this gap and explored the role of social media and magazines in the intention to buy ethical apparel produced by sustainable apparel brands. The paper builds on the theory of planned behavior to model the relationships between different types of media genres (i.e., fashion magazines, specialized magazines, social media hosted by sustainable organizations, eco-activists and sustainable 
MEDIA AND CONSUMPTION OF SUSTAINABLE APPAREL

apparel brands and social media hosted by fashion bloggers and fast fashion brands) and the intention to buy ethical apparel and potential mechanisms for explaining these relationships (i.e., attitudes, norms and self-efficacy beliefs). As such, our paper adopts a consumer-driven perspective (Gabrielli et al., 2013), and thus differs from scholars approaching sustainable apparel from an economic perspective (de Brito et al., 2008; Nagurney and Yu, 2012).

\section{Literature review}

\section{Sustainability in the Fashion Industry}

Sustainability overlaps with the notion of corporate social responsibility (CSR). CSR includes respect for juridical and ethical guidelines, fair treatment of employees and the environment, and preventing harmful side-effects caused by organizational activities (Mohr et al., 2001; Reilly and Hynan, 2014). Sustainable apparel is associated with valuing CSR and producing garment in a socially, ethically and environmentally responsible manner (Joergens, 2006; Niinimäki, 2010). Sustainable apparel is not only produced by companies who perceive sustainability as a defining feature of their clothing (e.g., Patagonia, People Tree, Eileen Fisher). In the past, fast fashion brands (e.g., Zara, H\&M, Primark) were known to disregard CSR (Arrigo, 2013) because of their focus on efficient production processes (Cachon and Swinney, 2011; Segre Reinach, 2005). However, recently they have integrated sustainability into their clothing lines.

Many corporations communicate about sustainability, such communication is defined as corporate sustainability communications (CSC) (Signitzer and Prexl, 2007). CSC includes three categories: social aspects, environmental aspects and consumer involvement (Strähle et al., 2015). First, CSC regarding social aspects refers to communicating about satisfying labor conditions for employees (Strähle et al., 2015). Sustainable apparel brands are highly attentive to socially responsible labor conditions. Fast fashion companies have also become more transparent regarding working conditions (Shen, 2014). Because fast fashion companies have 


\section{MEDIA AND CONSUMPTION OF SUSTAINABLE APPAREL}

been linked with unsafe workplaces and poor treatment of employees in the past (Adams, 2002; Arrigo, 2013), they have incorporated actions to improve their labor conditions (e.g., the "Sustainability Commitment" code of conduct of H\&M which commits suppliers to labor regulations).

Second, CSC regarding environmental aspects refers to communicating about the impact of production practices on the environment (Strähle et al., 2015). Sustainable apparel brands define themselves by environmentally responsible production processes, such as using eco-friendly fibers (Chen and Burns, 2006). Also, companies focusing on fast fashion have introduced sustainable clothing lines (e.g., the "Conscious Collection" of H\&M which is produced out of organic cotton).

Third, CSC regarding consumer involvement refers to communicating about mindful consumption and clothing disposal habits (Strähle et al., 2015). Such communication includes information about the usage phase and durability of the clothing, potential use of renewable materials, and garment recycling opportunities (Strähle et al., 2015).

Although the fashion industry has become more attentive to sustainability, most consumers disregard sustainability when buying clothing (Boulstridge and Carrigan, 2000; Mohr et al., 2001). While buying unsustainable apparel has environmental and social consequences, it does not directly affect the consumer's own well-being (Chan and Wong, 2012). As such, consumers are not often willing to bring sacrifices, such as paying a premium price and unfashionable design (Chan and Wong, 2012; Joergens, 2006). Consumers also lack knowledge about sustainable apparel (Hill and Lee, 2012; Ritch and Schröder, 2012). They find it hard to recognize brands that are truly sustainable (McNeill and Moore, 2015). Some consumers even doubt the credibility of CSC because of corporate greenwashing (Lee et al., 2013). Greenwashing refers to companies positioning themselves as 'green' although they do not behave in a sustainable manner (Strähle et al., 2015). 
MEDIA AND CONSUMPTION OF SUSTAINABLE APPAREL

As such, it is important to identify sources that are successful in informing (and convincing) consumers about sustainability in fashion. In this view, social media (Reilly and Hynan, 2014; Rocamora, 2012) and magazines (Winge, 2008) may be important media to communicate about sustainable apparel. However, little is known about how exposure to such media content affects individuals' cognitions concerning sustainable apparel.

\section{Theory of Planned Behavior}

The theory of planned behavior (Ajzen, 1991) may explain the relationships between media use and cognitions regarding sustainable apparel. This theory states that exposure to media messages containing information about a particular behavior (e.g., exposure to social media and magazine content on buying sustainable apparel) influences a set of cognitions that explain individuals' intention to engage in that behavior (e.g., intention to buy sustainable apparel). This intention subsequently predicts individuals' likelihood to enact that behavior (e.g., buying sustainable apparel).

The set of cognitions includes attitudes, norms and self-efficacy beliefs. Attitudes toward buying sustainable apparel refer to the extent to which a consumer holds favorable outcome beliefs regarding buying sustainable apparel (Ajzen, 1991). Norms include subjective and descriptive norms (Connell and Kozar, 2012). Subjective norms regarding sustainable apparel can be understood as the pressure from the social environment (e.g., family, friends, or colleagues) to buy sustainable apparel and the motivation to comply with this pressure (Ajzen, 1991; Connell and Kozar, 2012). Descriptive norms regarding sustainable apparel refer to the extent to which individuals believe that their social environment buys sustainable apparel (Connell and Kozar, 2012). Although the theory of planned behavior only includes subjective norms, literature (Connell and Kozar, 2012) has highlighted the importance of descriptive norms in shaping one's intentions. Finally, self-efficacy beliefs about sustainable apparel can 


\section{MEDIA AND CONSUMPTION OF SUSTAINABLE APPAREL}

be described as the extent to which individuals think they are able to buy sustainable apparel when they aim to buy such clothing (Ajzen, 1991).

The theory of planned behavior predicts that (1) cognitions affect behavioral intentions and subsequent behavior and (2) these cognitions are affected by media exposure. Regarding the first assumption, studies using the theory of planned behavior have confirmed the importance of attitudes and norms in explaining sustainable apparel buying intention. A survey study of Kang, Liu and Kim (2013) indicated that attitudes (i.e., believing that purchasing behavior could affect the environment) and subjective norms (i.e., believing that their social environment valued ethical consumption) positively predicted male and female college students' (18 to 29 years old) intention to purchase sustainable apparel. The survey study of Cowan and Kinley (2014) among men and women (18 years and older) found that attitudes (i.e., environmental concerns) and subjective norms to act green positively predicted individual's intention to purchase ethical fashion. Self-efficacy beliefs appeared to be nonsignificant in both studies.

Regarding the second assumption, little research has included media use when studying ethical fashion behavior. Studies examining other types of behavior (e.g., Beullens and Vandenbosch, 2016; Martino et al., 2005) have shown that media are an important socialization agent. Media have the ability to predict young individuals' cognitions toward certain behaviors. Potentially, media use may also shape cognitions about sustainable apparel behavior. Four media genres may be important to consider regarding sustainable apparel: (1) fashion magazines, (2) specialized magazines, (3) social media content of sustainable organizations, eco-activists, and sustainable apparel brands, and (4) social media content of fashion bloggers and fast fashion brands. Studies examining other types of behavior (e.g., Beullens and Vandenbosch, 2016; Martino et al., 2005) have suggested that the generated media-effect (i.e., 


\section{MEDIA AND CONSUMPTION OF SUSTAINABLE APPAREL}

on cognitions and intention) depends on the type of media (e.g., social media or magazines) and the media message (e.g., content of CSC).

Regarding the type of media, previous research has suggested that the richness of the medium may affect the attitudes toward the communicated CSR initiatives (Saat and Selamat, 2014). Social media are considered to be more rich media than magazines because of their interactive features. These features enable various communication actions between producers of media content and users of media content. The interactive nature of social media increases its potential to truly engage users in a 'community' (Reilly and Hynan, 2014). Social media are also considered to be more transparent as they allow a direct dialogue with the stakeholders (Lee et al., 2009). When brands post information on social media, stakeholders are invited to comment on the posts and thus to directly discuss the sustainability initiatives. As such, social media can be more influential in affecting consumers' attitudes as compared to traditional media, such as magazines.

Regarding the media content, media genres are likely to differ in their coverage of information on sustainability in fashion. Fashion magazines are focused on the trendiness of fashion (Gough-Yates, 2003). Fashion magazines have also been noted to report about sustainability in the fashion industry (e.g., The Green Issue of Vanity Fair, Winge, 2008). Such articles include stories about eco-conscious celebrities (Winge, 2008), information about the eco-friendliness of brands (Hoff, 2014a) and sustainability initiatives from fast fashion brands (e.g., Elle discussed H\&M’s 'Conscious Denim Collection', Hoff, 2014a).

Another potential information source about sustainable apparel may be specialized magazines, like National Geographic or The Ecologist (Beard, 2008). Such specialized magazines cover articles about the environment and ethical trade. As such, specialized magazines may be expected to support sustainable apparel buying behavior. 
MEDIA AND CONSUMPTION OF SUSTAINABLE APPAREL

Research has shown that companies in general (Reilly and Hynan, 2014), but also sustainable apparel brands (Fuentes, 2015), use social media to inform about CSR activities. Also, eco-activists, such as Livia Firth, and sustainable organizations, such as eco-age, inform consumers about sustainability in fashion on social media. Therefore, social media hosted by sustainable organizations, eco-activists, and sustainable apparel brands, can be expected to provide a rich platform to discuss the ethical component of fashion (Shen et al., 2014) and promote sustainable apparel extensively.

In addition, social media hosted by fast fashion brands and fashion bloggers have a similar focus as fashion magazines: They mainly inform consumers about the trendiness of clothing. Giving the increased sustainability interest of companies producing fast fashion, they may also post about the (sporadic) CSR activities fast fashion companies are involved in. Such messages can be expected to occur rather seldom, though. Research comparing companies with a true sustainability focus versus companies with sporadic sustainability activities (e.g., fast fashion companies) warns that the amount of social media messages regarding sustainability is higher among true green companies (Reilly and Hynan, 2014).

Overall, research suggests different media types cover to a different extent information about sustainable apparel. These media differences may result in different effects on cognitions and intention to buy sustainable apparel. Guided by the theory of planned behavior, we aim to further examine this:

Research Question: Are there differences in the relationships of exposure to 1) fashion magazines, 2) specialized magazines, 3) social media content of sustainable organizations, eco-activists and sustainable apparel brands 4) social media content of fashion bloggers and fast fashion brands with the intention to buy sustainable apparel and the attitudes, subjective and descriptive norms and self-efficacy beliefs on buying sustainable apparel? 


\section{MEDIA AND CONSUMPTION OF SUSTAINABLE APPAREL}

\section{Control Variables}

Fashion consciousness, involvement in sustainable organizations and gender will be included as control variables. Fashion consciousness has shown to affect one's lifestyle and buying behavior (O'Connor et al., 1997). Fashion conscious consumers can be expected to consume more fashion media and to have well-developed opinions regarding fashion. Also, prior involvement in sustainable organizations may be linked to more favorable cognitions about sustainable apparel as they promote this clothing style (Vuruskan and Fröhlich, 2012). Lastly, women are more interested in fashion than men (Morgan and Birtwistle, 2009). As such, women may consider to buy sustainable apparel more often than men. A graphical presentation of the variables in the theory of planned behavior and the control variables is displayed in figure 1 .

\section{[FIGURE 1: ABOUT HERE]}

\section{Method}

\section{Data Collection and Sample}

As young consumers are more concerned with fashion (Morgan \& Birtwistle, 2009) and more willing to buy sustainable products (Hill and Lee, 2012; Jin Ma et al., 2012), this study focuses on young adults. Data were collected among a convenience sample of 681 [identifying data deleted] adults aged between 18 to 26 years. The mean age was 22 years $(S D=1.97)$. The sample included more women (84.6\%) than men (15.4\%). An online standardized questionnaire was created using Qualtrics software. The questionnaire was subjected to a pilot study of 8 respondents. As a result, the wording of several questions was adapted. Confidentiality was assured and informed consent was requested by the start of the questionnaire. Respondents with incomplete data or unsigned informed consents were not included in the sample. Contact details of the researchers were added in case of comments or problems. The questionnaire was distributed mainly through the communication facilities of the University of the researchers [identifying data deleted] and on social media like Facebook and Instagram. To encourage 
MEDIA AND CONSUMPTION OF SUSTAINABLE APPAREL

participation, respondents' email addresses were entered in a lottery to win an incentive (reward cards of $€ 30)$.

Measures

Attitudes on sustainable apparel. An adapted version of the bipolar scale for attitudes of Fishbein et al. (2003) was used. Respondents evaluated whether "buying sustainable apparel is": (a) bad/good, (b) unpleasant/pleasant, (c) unwise/wise, (d) difficult/easy, (e) unnecessary/necessary and (f) uncomfortable/comfortable. Principal components analysis indicated that all items, except "difficult/easy", loaded on one factor with a loading higher than .40 (eigenvalue: 2.58 , explained variance: $43.03 \%$ ). Reliability analysis showed $\alpha$ would increase from .69 to .76 when this item would be removed. Therefore, the item "difficult/easy" was not included in the final variable that summed the scores of the five other items. Higher scores on this variable indicate a more positive attitude toward buying sustainable apparel.

Subjective norms on sustainable apparel. Subjective norms were measured using an adapted version of two items of Fishbein et al. (2003): "Most people who are important to me believe I should buy sustainable apparel" and "Most people who are important to me have a positive attitude toward sustainable apparel" $(r=.49, p<.001)$. Answer categories ranged from (1) "totally disagree" to (7) "totally agree." A sum variable of the scores on these two items was created. Higher scores indicate more positive subjective norms.

Descriptive norms on sustainable apparel. Respondents evaluated whether they agreed that "Most people who are important to them buy sustainable apparel." Answer categories ranged from (1) "totally disagree" to (7) "totally agree". Higher scores indicate more positive descriptive norms.

Self-efficacy beliefs on sustainable apparel. An adapted version of the self-efficacy scale of Fishbein et al. (2003) was used: "How certain are you that you can buy sustainable 
MEDIA AND CONSUMPTION OF SUSTAINABLE APPAREL

apparel?". Answer categories ranged from (1) "very certain I cannot" to (7) "very certain I can." Higher scores indicate more confidence in one's ability to buy sustainable apparel.

Behavioral intention to buy sustainable apparel in the future. The question "How likely is it that in the future, you will buy sustainable apparel?" (Fishbein et al., 2003) was included. Responses ranged from (1) "very unlikely" to (7) “very likely." Higher scores indicate a higher intention to buy sustainable apparel. For descriptive purposes, we created an additional variable that divided respondents into "high intenders" (score 6 or 7) and "low intenders" (score 5 or lower).

Exposure to fashion magazines. Respondents indicated how often they read fashion magazines, such as Elle, Vogue, and GQ. Answer categories ranged from (1) "almost never" to (7) “almost always." Higher scores indicate higher exposure to magazine content regarding fashion.

Exposure to specialized magazines. Respondents indicated how often they read magazines, such as National Geographic, GPM, and Animal Times. Answer categories ranged from (1) "almost never" to (7) "almost always." Higher scores indicate higher levels of exposure to magazine content regarding ethical and environmental issues.

Exposure to social media content of sustainable organizations, eco-activists, and sustainable apparel brands. A three item-scale was developed $(\alpha=.70)$. Respondents indicated how often they consulted "sustainable organizations like PETA, Unicef, Fair Wear Foundation on Facebook, Instagram or other social media", "blogs about sustainability or activists/celebrities like Livia Firth who promote sustainability" and "sustainable apparel brands such as Filippa K, JBC and Jack Wolfskin on Facebook, Instagram or other social media." Answer categories ranged from (1) "almost never" to (7) "almost always." The items of the scale were summed. Higher scores indicate higher levels of exposure to sustainable apparel information on social media. 
MEDIA AND CONSUMPTION OF SUSTAINABLE APPAREL

Exposure to social media content of fashion bloggers and fast fashion brands. Respondents indicated how often they consulted "fashion blogs such as Ghent Streetstyle, Polienne, Fashionata en Dogs \& Dresses" and "fast fashion brands such as Zara, H\&M, and Primark on Facebook, Instagram or other social media" $(r=.46, p<.001)$. Answer categories ranged from (1) "almost never" to (7) "almost always." The items of the scale were summed. Higher scores indicate higher levels of exposure to fast fashion information on social media.

Control variables. Fashion consciousness was measured using an adapted version of the fashion awareness scale of Tigert, Ring en King (1976). Four statements, such as "I am interested in fashion" and "I keep up-to-date on the latest fashion trends", were evaluated by respondents. Answer categories ranged from (1) "not agree at all” to (7) "totally agree." A principal components analysis (eigenvalue: 3.20; explained variance: $79.90 \%$ ) yielded one factor with good internal reliability $(\alpha=.92)$. The items of the scale were summed. Higher scores on this measure are an indication of increased fashion consciousness.

Knowledge of sustainable organizations was measured by asking respondents whether they were familiar with eight selected organizations, such as the Fair Wear Foundation or Schone Kleren Campagne $(0=$ not familiar with the organization, $1=$ familiar with the organization). Items were summed into one variable. Higher scores indicate more knowledge of sustainable organizations.

Lastly, gender was assessed $(0=$ male, $1=$ female $)$.

\section{Analyses}

Data were checked for missing values, outliers, normality distribution (skewness $<3$, kurtosis $<10$ ), and linearity assumption. As described above, principal components analyses were conducted to validate the proposed factor structure of scales (Janssens et al., 2008). Next, descriptive analyses and correlation analyses were calculated. Conditional process analysis, 


\section{MEDIA AND CONSUMPTION OF SUSTAINABLE APPAREL}

using Hayes's OLS regression based tool PROCESS (Hayes, 2013), tested the research question (see figure 1). Exposure to the two types of social media content, specialized magazines and fashion magazines $(\mathrm{X})$ were entered as predictors. Respondents' intention to buy sustainable apparel in the future was entered as the dependent variable (Y), while attitudes, subjective norms, descriptive norms and self-efficacy beliefs were included as mediating variables operating in parallel (M). Fashion consciousness, knowledge of sustainable organizations and gender were entered as control variables.

\section{Results}

\section{Descriptive Statistics}

Table 1 displays the descriptive statistics. Respondents were irregularly exposed to social media content of environmental organizations, eco-activists and sustainable apparel brands $(M=5.85$, $S D=3.40)$, social media content of fashion bloggers and fast fashion brands $(M=5.08, S D=$ 3.18), specialized magazines $(M=2.25, S D=1.48)$ and fashion magazines $(M=2.68, S D=$ 1.73). On average, they showed highly positive attitudes toward sustainable apparel $(M=25.71$, $S D=4.22)$ and indicated they would buy sustainable apparel in the future $(M=4.22, S D=$ 1.62). However, this intention was not so strong as illustrated by the distribution of high- and low intenders. A total of $74.7 \%$ of the respondents were low intenders, while $25.3 \%$ could be considered as high intenders. Respondents indicated that they thought that their social environment rarely bought sustainable apparel $(M=2.86, S D=1.14)$ and did not believe that their social environment favored buying sustainable apparel $(M=7.32, S D=2.34)$. Respondents also expressed feelings of uncertainty regarding their own capacities to buy sustainable apparel $(M=3.87, S D=1.52)$. Lastly, respondents indicated on average to consider themselves as fashion conscious $(M=16.84, S D=6.01)$ and had an average knowledge of sustainable organizations $(M=3.60, S D=1.20)$.

[TABLE 1: ABOUT HERE] 


\section{MEDIA AND CONSUMPTION OF SUSTAINABLE APPAREL}

\section{Correlation Analyses}

Correlations between all variables of interest were calculated and are shown in Table 2. These correlations support significant relationships among exposure to social media content of environmental organizations, eco-activists and sustainable apparel brands and attitudes, subjective and descriptive norms, self-efficacy beliefs and intention $(p<.001)$. Exposure to social media content of fashion bloggers and fast fashion brands correlated significantly with descriptive norms $(p<.05)$ and self-efficacy beliefs $(p<.001)$, but not with the other cognitions. Exposure to specialized magazines correlated significantly with subjective norms $(p<.001)$, descriptive norms $(p<.01)$ and intention $(p<.01)$, but not with attitudes. Lastly, null findings were found between exposure to fashion magazines and the cognitions under scrutiny.

\section{[TABLE 2: ABOUT HERE]}

\section{Conditional Process Model}

A conditional process model (see Figure 1) estimating whether attitudes (M1), subjective norms (M2), descriptive norms (M3) and self-efficacy beliefs (M4) mediated the relationships between exposure to social media content of sustainable organizations, eco-activists and sustainable apparel brands (X1), social media content of fashion bloggers and fast fashion brands (X2), specialized magazines (X3), fashion magazines (X4) and the intention to buy sustainable apparel in the future (Y) was tested.

\section{[TABLE 3: ABOUT HERE]}

Table 3 gives an overview of the results of this analysis. Data indicated that exposure to social media content of sustainable organizations, eco-activists and sustainable apparel brands was a significant positive direct predictor of attitudes $(\beta=.27, L L C I / U L C I=.16 / .38)$, subjective norms $(\beta=.21, L L C I / U L C I=.15 / .27)$, descriptive norms $(\beta=.07, L L C I / U L C I=.04 / .10)$ and self-efficacy $(\beta=.13, L L C I / U L C I=.09 / .17)$. Specialized magazines were not significantly related to any of the cognitions. 
MEDIA AND CONSUMPTION OF SUSTAINABLE APPAREL

Exposure to social media content of fashion bloggers and fast fashion brands was a significant negative direct predictor of attitudes $(\beta=-.22, L L C I / U L C I=-.37 /-.08)$, subjective norms $(\beta=-.17, L L C I / U L C I=-.25 /-.10)$, descriptive norms $(\beta=-.06, L L C I / U L C I=-.10 /-.02)$ and self-efficacy $(\beta=-.13, L L C I / U L C I=-.18 /-.08)$. Fashion magazines positively predicted self-efficacy $(\beta=.14, L L C I / U L C I=.05 / .23)$, but not attitudes or norms.

In addition, attitudes, norms, and self-efficacy were tested as direct predictors of the intention to buy sustainable apparel. Results indicated that attitudes $(\beta=.05, L L C I / U L C I=$ $.02 / .07)$, descriptive norms $(\beta=.24, L L C I / U L C I=.13 / .35)$ and self-efficacy $(\beta=.16$, $L L C I / U L C I=.08 / .24)$ were found to significantly positively predict the intention. Subjective norms did not significantly predict the intention. Moreover, social media content of sustainable organizations, eco-activists, and sustainable apparel brands also had a direct relationship ( $\beta$ $=.09, L L C I / U L C I=.05 / .13)$ with the intention to buy sustainable apparel. No other direct relationships between media use and intention were found.

The significance of indirect relationships was further examined. The total indirect effect of exposure to social media content of sustainable organizations, eco-activists, and brands sustainable apparel brands on intention was $.06(L L C I / U L C I=.04 / .08)$. The indirect effect of exposure to social media content of sustainable organizations, eco-activists and sustainable apparel brands on intention through the cognitions was $.01(L L C I / U L C I=.00 / .02)$ for attitudes, $.02(L L C I / U L C I=.01 / .03)$ for descriptive norms, and $.02(L L C I / U L C I=.01 / .04)$ for selfefficacy beliefs.

The total indirect effect of exposure to social media content of fashion bloggers and fast fashion brands on intention was $-.05(L L C I / U L C I=-.08 /-.03)$. The indirect effect of social media content of fashion bloggers and fast fashion brands on intention through the cognitions was $-.01(L L C I / U L C I=-.03 / .00)$ for attitudes, $-.01(L L C I / U L C I=-.03 / .00)$ for descriptive norms and -.02 (LLCI/ULCI = -.04/-.01) for self-efficacy beliefs. 
MEDIA AND CONSUMPTION OF SUSTAINABLE APPAREL

In sum, exposure to social media content of sustainable organizations, eco-activists and sustainable apparel brands and exposure to social media content of fashion bloggers and fast fashion brands were respectively positively and negatively related to the intention to buy sustainable apparel through attitudes, descriptive norms and self-efficacy. Subjective norms had no mediating value. The relationship between exposure to fashion magazines and intentions to buy sustainable apparel was mediated by self-efficacy, but not by the other cognitions.

\section{Discussion}

Little is known about the role of different media genres in individuals' cognitions about sustainable apparel. The current study addressed this gap by using the theory of planned behavior (Ajzen, 1991) and found that exposure to social media has the potential to shape young adults' attitudes, norms and self-efficacy beliefs regarding sustainable apparel. Social media content of sustainable organizations, eco-activists, and sustainable apparel brands encouraged the adoption of positive attitudes, subjective norms, descriptive norms and selfefficacy beliefs regarding sustainable apparel. In contrast, social media content of fashion bloggers and fast fashion brands discouraged the adoption of such positive cognitions. Fashion magazines played a positive role in young adults' self-efficacy beliefs. Fashion magazines enhanced readers' beliefs about their abilities to purchase sustainable apparel. Specialized magazines did not predict the cognitions about sustainable apparel. It is possible that this media genre focuses on sustainability in general but does not cover enough information about sustainability in fashion to have an impact on cognitions regarding sustainable apparel.

In line with the propositions of the theory of planned behavior (Ajzen, 1991) and prior literature on risk behavior (Beullens and Vandenbosch, 2016; Martino et al., 2005) we also found that the relationships between social media use and the intention to buy sustainable apparel were mediated through three cognitive processes. 


\section{MEDIA AND CONSUMPTION OF SUSTAINABLE APPAREL}

First, attitudes mediated the relationships between social media use and the intention to buy sustainable apparel. Social media content of sustainable organizations, eco-activists and sustainable apparel brands related to an increased number of perceived positive outcomes of buying ethical fashion. Subsequently, these positive attitudes were associated with a higher intention to buy sustainable apparel. Social media content of fashion bloggers and fast fashion brands was linked to a decrease in perceived positive outcomes of buying ethical fashion. In turn, these negative attitudes negatively predicted the intention to buy sustainable apparel.

Second, descriptive norm perceptions mediated the relationships between social media use and the intention to buy sustainable apparel. The more young adults consumed social media content of sustainable organizations, eco-activists and sustainable apparel brands, the more they believed close relatives bought sustainable apparel. In turn, these descriptive norm perceptions positively predicted their buying intentions. When looking at social media content of fashion bloggers and fast fashion brands, we found that the more young adults were exposed to such media content, the less they believed close relatives bought sustainable apparel. These descriptive norms negatively predicted their buying intentions.

In contrast to previous research (Cowan and Kinley, 2014; Kang et al., 2013), subjective norms did not predict the intention to buy sustainable apparel. Potentially, subjective norms cannot be learned from social media channels hosted by fashion bloggers, activists or organizations in the fashion industry. Future research may examine whether messages that are posted by close relatives on social media about fashion may exert an influence on subjective norms, though.

Third, self-efficacy beliefs mediated the relationships between social media use and intention to buy sustainable apparel. Social media content of fashion bloggers and fast fashion brands related to increased feelings of uncertainty regarding one's ability to buy sustainable apparel, while social media content of sustainable organizations, eco-activists and sustainable 
MEDIA AND CONSUMPTION OF SUSTAINABLE APPAREL

apparel brands correlated with a boost in one's self-efficacy beliefs, which in turn predicted the intention.

Self-efficacy beliefs also positively mediated the relationship between fashion magazines and the intention to buy sustainable apparel. Future research may investigate whether this relationship can be explained by the provision of positive role models wearing eco-friendly clothing (Winge, 2008) and the provision of information on the eco-friendliness of different brands (Hoff, 2014a).

\section{Limitations}

As with all studies, the present study has a number of shortcomings. First, the study relied on a convenience sample of young [identifying information deleted] adults. Therefore, results should be generalized with caution. For instance, research has revealed that respondents belonging to the babyboom and swing generation are more focused on the quality of clothing, less interested in fashionable design and highly value fair trade clothing. Potentially, an older age group would respond differently to messages about sustainable apparel. Also, our sample included more women than men. This is not surprising as existing research shows that fashion is especially an interest of young women (Morgan and Birtwistle, 2009).

Second, the cross-sectional design limits our ability to draw conclusions regarding causality. Media effect theories (e.g., reinforcing spirals theory, Slater, 2007) highlight the potential of cognitions to influence the selection of media content and vice versa. Such dynamic processes between media use and cognitions about sustainable apparel can be captured in longitudinal research. Future experimental research may further examine the causal order of such relations.

Third, in line with prior research on consumption behavior (Cowan and Kinley, 2014; Kang et al., 2013), we focused on the relationships between media and the intention to buy sustainable apparel. Although many studies have demonstrated that intention is a strong 


\section{MEDIA AND CONSUMPTION OF SUSTAINABLE APPAREL}

predictor of actual behavior (George, 2004; Pelling and White, 2009), we did not address links with actual buying behavior. Therefore, it is difficult to say whether respondents will actually buy sustainable apparel in the future. Future research may examine this issue with attention to potential barriers for acting upon one's intention. Particular barriers for sustainable apparel may be the consumers' lack of knowledge about sustainable apparel brands, premium price and unfashionable design (Joergens, 2006).

\section{Implications}

Sustainable apparel brands should be aware of the potential that social media offer to promote sustainable buying behavior. The present study indicates that exposure to social media content about sustainable apparel is a direct and indirect predictor of intentions to buy sustainable apparel. However, our results also showed that young consumers are rarely exposed to such media. As such, ethical fashion companies are encouraged to develop a strategy to attract more young social media users as followers of their social media pages. The popularity of social media pages promoting sustainable apparel can be enhanced by posting more vivid (e.g. videos) and interactive (e.g. contests) posts (de Vries et al., 2012) and the provision of promotional incentives (Muk, 2013).

Our results further indicated that social media posts of sustainable organizations, ecoactivists, and sustainable apparel brands are advised to contain messages that are likely to affect consumers' attitudes toward sustainable apparel, descriptive norm perceptions and self-efficacy beliefs as these cognitions were found to predict buying intention. Ethical fashion companies should, therefore, consider producing posts that are targeted at increasing such cognitions. For instance, to enhance self-efficacy, social media posts of sustainable organizations and ecoactivists should consider focusing on information about which fashion brands are sustainable. Such information is important as consumers indicate to lack knowledge about the names of sustainable apparel brands (McNeill and Moore, 2015). 
MEDIA AND CONSUMPTION OF SUSTAINABLE APPAREL

Also, this research found that fashion magazines positively predicted self-efficacy beliefs. Although fashion magazines are mainly concerned with the trendiness of fashion (Gough-Yates, 2003), their coverage of news about sustainability in the fashion industry is effective. Brands should, therefore, consider to send out press releases on their sustainability initiatives.

Finally, our results showed that social media of fashion bloggers and fast fashion brands negatively predicted cognitions regarding sustainable apparel. Fashion bloggers enjoy a high credibility among young followers (Lee and Watkins, 2016; Pihl and Sandström, 2013). As such, sustainable apparel brands could consider enhancing their popularity by reaching out to fashion influencers (Muk, 2013). Also, fast fashion brands may consider communicating more about their sustainability initiatives. Such communication seems to be needed to encourage consumers to buy sustainable apparel collections produced by fast fashion companies.

In sum, the current study is one of the first to demonstrate the role of media in young consumers' intention to buy sustainable apparel. The results highlight the importance of social media to motivate individuals to invest in sustainable apparel. 


\section{References}

Adams, R.J. (2002), "Retail profitability and sweatshops: a global dilemma", Journal of Retailing and Consumer Services, Vol. 9 No. 3, pp. 147-153.

Ajzen, I. (1991), “The theory of planned behavior", Organizational Behavior and Human Decision Processes, Vol. 50 No. 2, pp. 179-211.

Arrigo, E. (2013), "Corporate responsibility management in fast fashion companies: the Gap Inc. case", Journal of Fashion Marketing and Management: An International Journal, Vol. 17 No. 2, pp. 175-189.

Balakrishnan, B.K.P.D., Dahnil, M.I. and Yi, W.J. (2014), “The Impact of Social Media Marketing Medium toward Purchase Intention and Brand Loyalty among Generation Y", Procedia - Social and Behavioral Sciences, Vol. 148, pp. 177-185.

Beard, N.D. (2008), “The Branding of Ethical Fashion and the Consumer: A Luxury Niche or Mass-market Reality?", Fashion Theory: The Journal of Dress, Body \& Culture, Vol. 12 No. 4, pp. 447-468.

Beullens, K. and Vandenbosch, L. (2016), “A Conditional Process Analysis on the Relationship Between the Use of Social Networking Sites, Attitudes, Peer Norms, and Adolescents' Intentions to Consume Alcohol”, Media Psychology, Vol. 19 No. 2, pp. 310-333.

Boulstridge, E. and Carrigan, M. (2000), "Do consumers really care about corporate responsibility? Highlighting the attitude-behaviour gap", Journal of Communication Management, Vol. 4 No. 4, pp. 355-368.

de Brito, M.P., Carbone, V. and Blanquart, C.M. (2008), "Towards a sustainable fashion retail supply chain in Europe: Organisation and performance", International Journal of Production Economics, Vol. 114 No. 2, pp. 534-553.

Cachon, G.P. and Swinney, R. (2011), “The Value of Fast Fashion: Quick Response, Enhanced Design, and Strategic Consumer Behavior”, Management Science, Vol. 57 No. 4, pp. 778-795. Chan, T. and Wong, C.W.Y. (2012), "The consumption side of sustainable fashion supply chain: Understanding fashion consumer eco-fashion consumption decision", Journal of Fashion Marketing and Management: An International Journal, Vol. 16 No. 2, pp. 193-215.

Chen, H.L. and Burns, L.D. (2006), "Environmental Analysis of Textile Products", Clothing and Textiles Research Journal, Vol. 24 No. 3, pp. 248-261.

Clark, H. (2008), "SLOW + FASHION—an Oxymoron—or a Promise for the Future ...?", Fashion Theory: The Journal of Dress, Body \& Culture, Vol. 12 No. 4, pp. 427-446.

Connell, K.Y.H. and Kozar, J.M. (2012), “Social Normative Influence: An Exploratory Study Investigating its Effectiveness in Increasing Engagement in Sustainable Apparel-Purchasing 
Behaviors", Journal of Global Fashion Marketing, Vol. 3 No. 4, pp. 172-179.

Cowan, K. and Kinley, T. (2014), "Green spirit: consumer empathies for green apparel: Consumer empathies for green apparel”, International Journal of Consumer Studies, Vol. 38 No. 5, pp. 493-499.

Fishbein, M., Hennessy, M., Yzer, M.C. and Douglas, J. (2003), "Can we explain why some people do and some people do not act on their intentions?", Psychology, Health \& Medicine, Vol. 8 No. 1, pp. 3-18.

Fuentes, C. (2015), "Images of responsible consumers: organizing the marketing of sustainability", International Journal of Retail \& Distribution Management, Vol. 43 No. 4/5, pp. 367-385.

Gabrielli, V., Baghi, I. and Codeluppi, V. (2013), "Consumption practices of fast fashion products: a consumer-based approach", Journal of Fashion Marketing and Management: An International Journal, Vol. 17 No. 2, pp. 206-224.

George, J.F. (2004), "The theory of planned behavior and Internet purchasing", Internet Research, Vol. 14 No. 3, pp. 198-212.

Gough-Yates, A. (2003), Understanding Women's Magazines: Publishing, Markets and Readerships in Late-Twentieth Century Britain, Routledge.

Hayes, A.F. (2013), Introduction to Mediation, Moderation, and Conditional Process Analysis: A Regression-Based Approach, Guilford Press.

Hill, J. and Lee, H. (2012), "Young Generation Y consumers' perceptions of sustainability in the apparel industry", Journal of Fashion Marketing and Management: An International Journal, Vol. 16 No. 4, pp. 477-491.

Hobson, J. (2013), “To die for? The health and safety of fast fashion”, Occupational Medicine, Vol. 63 No. 5, pp. 317-319.

Hoff, V. (2014a), "7 Eco-Friendly Fashion Labels to Know Now", available at: http://www.elle.com/fashion/g8913/best-eco-friendly-fashion-brands/?slide=1.

Hoff, V. (2014b), "H\&M's New Conscious Denim Collection Is Eco-Friendly and Oh-SoCool", available at: http://www.elle.com/fashion/news/a15519/hm-conscious-denimcollection/.

Janssens, W., De Pelsmacker, P. and Van Kenhove, P. (2008), Marketing Research with SPSS, Pearson Education.

Jin Ma, Y., Littrell, M.A. and Niehm, L. (2012), “Young female consumers' intentions toward fair trade consumption", International Journal of Retail \& Distribution Management, Vol. 40 No. 1, pp. 41-63. 
Joergens, C. (2006), “Ethical fashion: myth or future trend?", Journal of Fashion Marketing and Management: An International Journal, Vol. 10 No. 3, pp. 360-371.

Kang, J., Liu, C. and Kim, S.-H. (2013), "Environmentally sustainable textile and apparel consumption: the role of consumer knowledge, perceived consumer effectiveness and perceived personal relevance: Environmentally sustainable textile and apparel consumption”, International Journal of Consumer Studies, Vol. 37 No. 4, pp. 442-452.

Lee, J.E. and Watkins, B. (2016), “YouTube vloggers' influence on consumer luxury brand perceptions and intentions", Journal of Business Research, Vol. 69 No. 12, pp. 5753-5760.

Lee, K., Oh, W.-Y. and Kim, N. (2013), "Social Media for Socially Responsible Firms: Analysis of Fortune 500's Twitter Profiles and their CSR/CSIR Ratings", Journal of Business Ethics, Vol. 118 No. 4, pp. 791-806.

Lee, M.S.W., Motion, J. and Conroy, D. (2009), “Anti-consumption and brand avoidance", Journal of Business Research, Vol. 62 No. 2, pp. 169-180.

Luz, C. (2007), "Waste couture: Environmental impact of the clothing industry", Environmental Health Perspectives, Vol. 115 No. 9, p. A448.

Martino, S.C., Collins, R.L., Kanouse, D.E., Elliott, M. and Berry, S.H. (2005), "Social cognitive processes mediating the relationship between exposure to television's sexual content and adolescents' sexual behavior.", Journal of Personality and Social Psychology, Vol. 89 No. 6, pp. 914-924.

McNeill, L. and Moore, R. (2015), "Sustainable fashion consumption and the fast fashion conundrum: fashionable consumers and attitudes to sustainability in clothing choice: Sustainable fashion consumption and the fast fashion conundrum", International Journal of Consumer Studies, Vol. 39 No. 3, pp. 212-222.

Mohr, L.A., Webb, D.J. and Harris, K.E. (2001), "Do Consumers Expect Companies to be Socially Responsible? The Impact of Corporate Social Responsibility on Buying Behavior", The Journal of Consumer Affairs, Vol. 35 No. 1, pp. 45-72.

Morgan, L.R. and Birtwistle, G. (2009), “An investigation of young fashion consumers' disposal habits”, International Journal of Consumer Studies, Vol. 33 No. 2, pp. 190-198.

Muk, A. (2013), "What factors influence millennials to like brand pages?", Journal of Marketing Analytics, Vol. 1 No. 3, pp. 127-137.

Nagurney, A. and Yu, M. (2012), "Sustainable fashion supply chain management under oligopolistic competition and brand differentiation", International Journal of Production Economics, Vol. 135 No. 2, pp. 532-540.

Niinimäki, K. (2010), "Eco-clothing, consumer identity and ideology", Sustainable 


\section{MEDIA AND CONSUMPTION OF SUSTAINABLE APPAREL}

Development, Vol. 18 No. 3, pp. 150-162.

Niinimäki, K. and Hassi, L. (2011), "Emerging design strategies in sustainable production and consumption of textiles and clothing", Journal of Cleaner Production, Vol. 19 No. 16, pp. $1876-1883$.

O’Connor, E., Friel, S. and Kelleher, C. (1997), "Fashion consciousness as a social influence on lifestyle behaviour in young Irish adults", Health Promotion International, Vol. 12 No. 2, pp. 135-139.

Ozdamar Ertekin, Z. and Atik, D. (2015), "Sustainable Markets: Motivating Factors, Barriers, and Remedies for Mobilization of Slow Fashion", Journal of Macromarketing, Vol. 35 No. 1, pp. 53-69.

Pelling, E.L. and White, K.M. (2009), “The Theory of Planned Behavior Applied to Young People's Use of Social Networking Web Sites”, CyberPsychology \& Behavior, Vol. 12 No. 6, pp. 755-759.

Pihl, C. and Sandström, C. (2013), "Value creation and appropriation in social media - the case of fashion bloggers in Sweden", International Journal of Technology Management, Vol. 61 No. 3/4, p. 309.

Reilly, A.H. and Hynan, K.A. (2014), "Corporate communication, sustainability, and social media: It's not easy (really) being green”, Business Horizons, Vol. 57 No. 6, pp. 747-758.

Ritch, E.L. and Schröder, M.J. (2012), “Accessing and affording sustainability: the experience of fashion consumption within young families: Experience of fashion consumption", International Journal of Consumer Studies, Vol. 36 No. 2, pp. 203-210.

Rocamora, A. (2012), "Hypertextuality and remediation in the fashion media: The case of fashion blogs", Journalism Practice, Vol. 6 No. 1, pp. 92-106.

Saat, R.M. and Selamat, M.H. (2014), “An Examination of Consumer's Attitude towards Corporate Social Responsibility (CSR) Web Communication Using Media Richness Theory”, Procedia - Social and Behavioral Sciences, Vol. 155, pp. 392-397.

Segre Reinach, S. (2005), "China and Italy: Fast Fashion versus Prêt à Porter.Towards a New Culture of Fashion", Fashion Theory: The Journal of Dress, Body \& Culture, Vol. 9 No. 1, pp. 43-56.

Shen, B. (2014), "Sustainable fashion supply chain: Lessons from H\&M”, Sustainability, Vol. 6 No. 9, pp. 6236-6249.

Shen, B., Zheng, J.-H., Chow, P.-S. and Chow, K.-Y. (2014), "Perception of fashion sustainability in online community", The Journal of The Textile Institute, Vol. 105 No. 9, pp. 971-979. 
Signitzer, B. and Prexl, A. (2007), "Corporate Sustainability Communications: Aspects of Theory and Professionalization”, Journal of Public Relations Research, Vol. 20 No. 1, pp. 119.

Slater, M.D. (2007), "Reinforcing Spirals: The Mutual Influence of Media Selectivity and Media Effects and Their Impact on Individual Behavior and Social Identity", Communication Theory, Vol. 17 No. 3, pp. 281-303.

Steele, J.R. and Brown, J.D. (1995), “Adolescent room culture: Studying media in the context of everyday life", Journal of Youth and Adolescence, Vol. 24 No. 5, pp. 551-576.

Strähle, J., Will, C. and Freise, M. (2015), "Communication of sustainability at European fashion online shops", International Journal of Economics, Commerce and Management, Vol. 3 No. 7, pp. 71-86.

Taplin, I. (2014), "Who is to blame? A re-examination of fast fashion after the 2013 factory disaster in Bangladesh", Critical Perspectives on International Business, Vol. 10 No. 1/2, pp. 72-83.

Tigert, D.J., Ring, L.J. and King, C.W. (1976), "Fashion involvement and buying behavior: a methodological study.", Advances in Consumer Research, Vol. 3 No. 1, pp. 46-52.

de Vries, L., Gensler, S. and Leeflang, P.S.H. (2012), "Popularity of Brand Posts on Brand Fan Pages: An Investigation of the Effects of Social Media Marketing”, Journal of Interactive Marketing, Vol. 26 No. 2, pp. 83-91.

Vuruskan, A. and Fröhlich, J. (2012), “Alternative Marketing Strategies in Commercial Eco Fashion".

Winge, T.M. (2008), “'Green Is the New Black': Celebrity Chic and the 'Green' Commodity Fetish", Fashion Theory: The Journal of Dress, Body \& Culture, Vol. 12 No. 4, pp. 511-524. 
Table 1

Descriptive Statistics

\begin{tabular}{|c|c|c|c|c|}
\hline & Min & Max & $M$ & $S D$ \\
\hline $\begin{array}{l}\text { Exposure to social media content of sustainable } \\
\text { organizations, eco-activists, and sustainable } \\
\text { apparel brands }\end{array}$ & 2.00 & 14.00 & 5.85 & 3.40 \\
\hline $\begin{array}{l}\text { Exposure to social media content of fashion } \\
\text { bloggers and fast fashion brands }\end{array}$ & 3.00 & 21.00 & 5.08 & 3.18 \\
\hline Exposure to specialized magazines & 1.00 & 7.00 & 2.25 & 1.48 \\
\hline Exposure to fashion magazines & 1.00 & 7.00 & 2.68 & 1.73 \\
\hline Attitudes on sustainable apparel & 5.00 & 35.00 & 25.71 & 4.22 \\
\hline Subjective norms on sustainable apparel & 2.00 & 14.00 & 7.32 & 2.34 \\
\hline Descriptive norms on sustainable apparel & 1.00 & 7.00 & 2.86 & 1.14 \\
\hline Self-efficacy beliefs on sustainable apparel & 1.00 & 7.00 & 3.87 & 1.52 \\
\hline Intention to buy sustainable apparel & 1.00 & 7.00 & 4.22 & 1.62 \\
\hline Fashion consciousness & 4.00 & 28.00 & 16.84 & 6.01 \\
\hline Knowledge of sustainable organizations & 0.00 & 8.00 & 3.60 & 1.20 \\
\hline
\end{tabular}




\section{MEDIA AND CONSUMPTION OF SUSTAINABLE APPAREL}

Table 2

\section{Correlations}

$\begin{array}{lllllllllll}1 & 2 & 3 & 4 & 5 & 6 & 7 & 8 & 9 & 10 & 11\end{array}$

1. Social media content of sustainable organizations, ecoactivists, and sustainable apparel brands

2. Social media content of fashion bloggers and fast fashion brands

3. Specialized magazines

\section{Fashion magazines}

5. Attitudes

6. Subjective norms

7. Descriptive norms

8. Self-efficacy beliefs

9. Intention

10. Fashion consciousness

11. Knowledge of sustainable organizations

1

$.42 * * * \quad 1$

$.39 * * * \quad .15 * * * \quad 1$

$.37 * * * \quad .61 * * * \quad .23 * * * \quad 1$

$\begin{array}{lllll}.17 * * * & .01 & .01 & .06 & 1\end{array}$

$\begin{array}{lllll}.26 * * * & -.07 & .17 * * * \quad .00 \quad .21 * * * & 1\end{array}$

$\begin{array}{llllll}.15 * * * & -.08 * & .12 * * & .00 & .05 & .40 * * *\end{array}$

$\begin{array}{llllllll}.16^{* * *} & -.16^{* * *} & .07 & -.01 & .10^{*} & .22^{* * *} & .26 * * * & 1\end{array}$

$\begin{array}{lllllllll}.26 * * * & -.04 & .12 * * & .06 & .20 * * * & .26 * * * & .27 * * * & .27 * * * & 1\end{array}$

$\begin{array}{llllllllll}.35 * * * & .66 * * * & .11 * * & .61 * * * & .07 & .01 & -.06 & -14 * * * & -.00 & 1\end{array}$

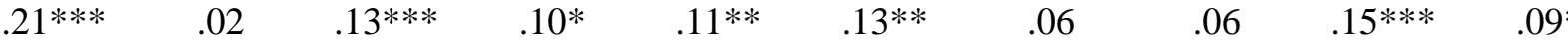

Note. ${ }^{*} p<.05, * * p<.01,{ }^{* * *} p<.001$ 


\section{MEDIA AND CONSUMPTION OF SUSTAINABLE APPAREL}

Table 3

Conditional process model (mediation) examining the conditional indirect relations between exposure to media content with young adults' intention to buy sustainable apparel

\begin{tabular}{|c|c|c|c|c|c|c|c|c|c|c|}
\hline & \multicolumn{2}{|c|}{ Attitudes } & \multicolumn{2}{|c|}{ Subjective norms } & \multicolumn{2}{|c|}{ Descriptive norms } & \multicolumn{2}{|c|}{ Self-efficacy } & \multicolumn{2}{|c|}{ Intention } \\
\hline & Coeff & $L L C I / U L C I$ & Coeff & $L L C I / U L C I$ & Coeff & $L L C I / U L C I$ & Coeff & $L L C I / U L C I$ & Coeff & $L L C I / U L C I$ \\
\hline Constant & $23.34 *$ & $21.97 / 24.72$ & $6.08 *$ & $5.34 / 6.82$ & $2.98 *$ & $2.61 / 3.35$ & $4.28 *$ & $3.80 / 4.76$ & .61 & $-.27 / 1.50$ \\
\hline $\begin{array}{l}\text { Social media content of } \\
\text { sustainable organizations, } \\
\text { eco-activists, and } \\
\text { sustainable apparel brands }\end{array}$ & $.27 *$ & $.16 / .38$ & $.21 *$ & $.15 / .27$ & $.07 *$ & $.04 / .10$ & $.13^{*}$ & $.09 / .17$ & $.09 *$ & $.05 / .13$ \\
\hline $\begin{array}{l}\text { Social media content of } \\
\text { fashion bloggers and fast } \\
\text { fashion brands }\end{array}$ & $-.22 *$ & $-.37 /-.08$ & $-.17 *$ & $-.25 /-.10$ & $-.06 *$ & $-.10 /-.02$ & $-.13 *$ & $-.18 /-.08$ & -.04 & $-.10 / .01$ \\
\hline Specialized magazines & -.21 & $-.44 / .03$ & .11 & $-.01 / .24$ & .03 & $-.03 / .10$ & -.03 & $-.11 / .05$ & .01 & $-.08 / .09$ \\
\hline Fashion magazines & .08 & $-.17 / .33$ & -.03 & $-.17 / .10$ & .05 & $-.02 / .12$ & $.14^{*}$ & $.05 / .23$ & .03 & $-.06 / .12$ \\
\hline Fashion consciousness & .04 & $-.03 / .12$ & .03 & $-.01 / .07$ & -.00 & $-.02 / .02$ & $-.03 *$ & $-.06 / .00$ & -.01 & $-.04 / .01$ \\
\hline $\begin{array}{l}\text { Knowledge of sustainable } \\
\text { organizations }\end{array}$ & .23 & $-.04 / .50$ & .11 & $-.03 / .26$ & .02 & $-.06 / .09$ & .02 & $-.07 / .11$ & .09 & $-.01 / .18$ \\
\hline Gender & .75 & $-.19 / 1.70$ & -.17 & $-.68 / .33$ & $-.49 *$ & $-.75 /-.24$ & $-.43^{*}$ & $-.76 /-.10$ & .31 & $-.03 / .65$ \\
\hline Attitudes & & & & & & & & & $.05^{*}$ & $.02 / .07$ \\
\hline Subjective norms & & & & & & & & & .05 & $-.01 / .10$ \\
\hline Descriptive norms & & & & & & & & & $.24 *$ & $.13 / .35$ \\
\hline Self-efficacy & & & & & & & & & $.16^{*}$ & $.08 / .24$ \\
\hline Model summary & \multicolumn{2}{|c|}{$R=.24, R^{2}=.06$} & \multicolumn{2}{|c|}{$R=.34, R^{2}=.12$} & \multicolumn{2}{|c|}{$R=.27, R^{2}=.07$} & \multicolumn{2}{|c|}{$R=.34, R^{2}=.11$} & \multicolumn{2}{|c|}{$R=.44, R^{2}=.19$} \\
\hline & \multicolumn{2}{|c|}{$F(5,909), p<.001$} & \multicolumn{2}{|c|}{$F(12,975), p<.001$} & \multicolumn{2}{|c|}{$F(7,513), p<.001$} & \multicolumn{2}{|c|}{$F(12,402), p<.001$} & \multicolumn{2}{|c|}{$F(14,720), p<.001$} \\
\hline
\end{tabular}

Note: $* p<.05, L L C I=$ Lower Level Confidence Interval, $U L C I=$ Upper Level Confidence Interval 


\section{MEDIA AND CONSUMPTION OF SUSTAINABLE APPAREL}

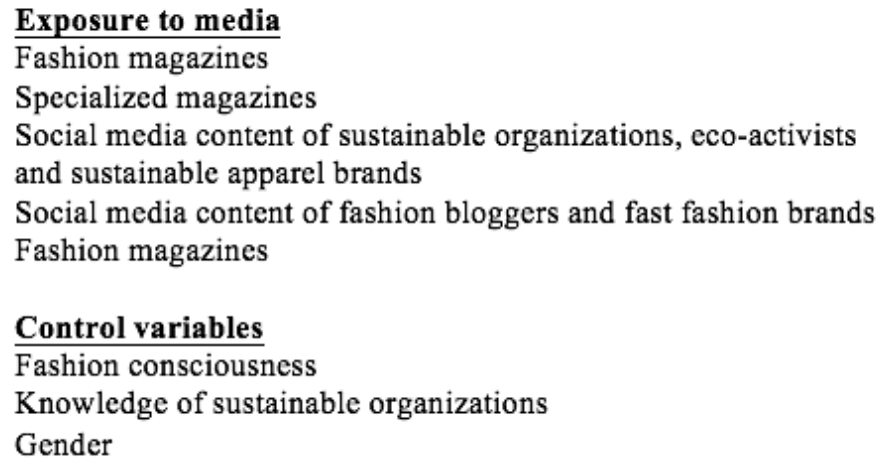

Social media content of fashion bloggers and fast fashion brands

Fashion magazines

\section{Control variables}

Fashion consciousness

Knowledge of sustainable organizations

Gender

Exposure to media and control variables

Figure 1. Conceptual diagram based on the theory of planned behavior for the relationships between the exposure to media content, cognitions toward sustainable apparel, and the behavioral intention to buy sustainable apparel in the future.

Note: The media variables and control variables were tested separately in relation to the different cognitions. They were visualized into one box to maintain a clear overview of the model. 